\section{Update on drug-eluting stents:}

\section{as good as it gets?}

Ajay K Jain MRCP, Specialist Registrar in Cardiology

Anthony Mathur PhD MRCP, Senior Lecturer; Honorary Consultant in Cardiology

Department of Cardiology, London Chest Hospital

\section{Clin Med 2007:7:401-4}

The widespread adoption of balloon expandable coronary stents in the 1990s brought about a significant improvement in the results of percutaneous coronary intervention (PCI). There was not only a reduction in the number of patients requiring emergency coronary artery bypass graft (CABG) but also a reduction in the occurrence of clinically significant restenosis within the treated artery and thus the need for target vessel revascularisation (TVR). ${ }^{1,2}$ However, it soon became apparent that in certain patient types, and some complex coronary artery lesion subsets, restenosis related to neointimal proliferation caused by the endothelial injury resulting from stent implantation remained a significant problem. The advent of drug-eluting stents (DES), metal stents coated with a polymer and a drug aimed at reducing neointimal proliferation, resulted in further significant reductions in the rates of restenosis. This led to a rapid adoption of DES in the percutaneous treatment of coronary artery disease (CAD). By the end of 2004 DES were used in up to $80 \%$ of PCIs in the USA.

Despite clinical evidence supporting the benefit of DES, longer follow-up studies have raised important questions about the safety and efficacy of DES in routine practice. Regardless of the clear improvement in the rates of restenosis in patients who receive DES in randomised controlled trials (RCT), the outcome data from 'real-world' registry collections of DES usage have been less impressive. Data have suggested no survival benefit between patients treated with bare metal stent (BMS) or DES. ${ }^{3}$ There have been numerous reports of abrupt stent occlusion due to stent thrombosis, ${ }^{4,5}$ and the ideal antiplatelet combination to optimise outcomes for PCI but minimise the risk of significant haemorrhage is yet to be established.

This review will discuss the role of DES in reducing in-stent restenosis, the risks of stent thrombosis and the risks and benefits of long-term dual antiplatelet therapy (DAPT).

\section{Drug-eluting stents and in-stent restenosis}

\section{The restenotic process}

The restenotic process in coronary stents comprises a series of complex but interrelated events. On the initiation of vessel injury, there is platelet activation followed by local thrombosis; an inflammatory reaction is also invoked neutrophils, monocytes and lymphocytes can be observed within mural thrombus within 1-5 days following percutaneous transluminal coronary angioplasty in animal models. Activated platelets and inflammatory mediators stimulate vascular smooth muscle cell (VSMC) proliferation, characterised by cell division, migration from the media and matrix secretion, causing neointimal proliferation. There may also be an immune reaction to the stent itself, characterised by chronic inflammation persisting weeks after implantation. Finally, there is vascular remodelling with adventitial fibroblast proliferation, adventitial thickening and increasing cell density. These processes occur at different rates and may occur to different extents depending on the device implanted, the lesion morphology and, importantly, the individual patient characteristics.

\section{Prevention of restenosis}

Through the prevention of early elastic recoil and later adventitial constriction, stents have managed to significantly attenuate the restenotic process following balloon angioplasty, but at the expense of exaggerated intimal hyperplasia leading to greater late lumen loss. Although the thrombotic and inflammatory mechanisms contribute to this process, VSMC proliferation and endothelial dysfunction appear to be a common pathway for neointimal formation, providing the most clinically relevant target to date for preventing restenosis. Furthermore, although antiplatelet and antithrombotic therapies such as aspirin, thienopyridines (clopidogrel and ticlopidine) and the

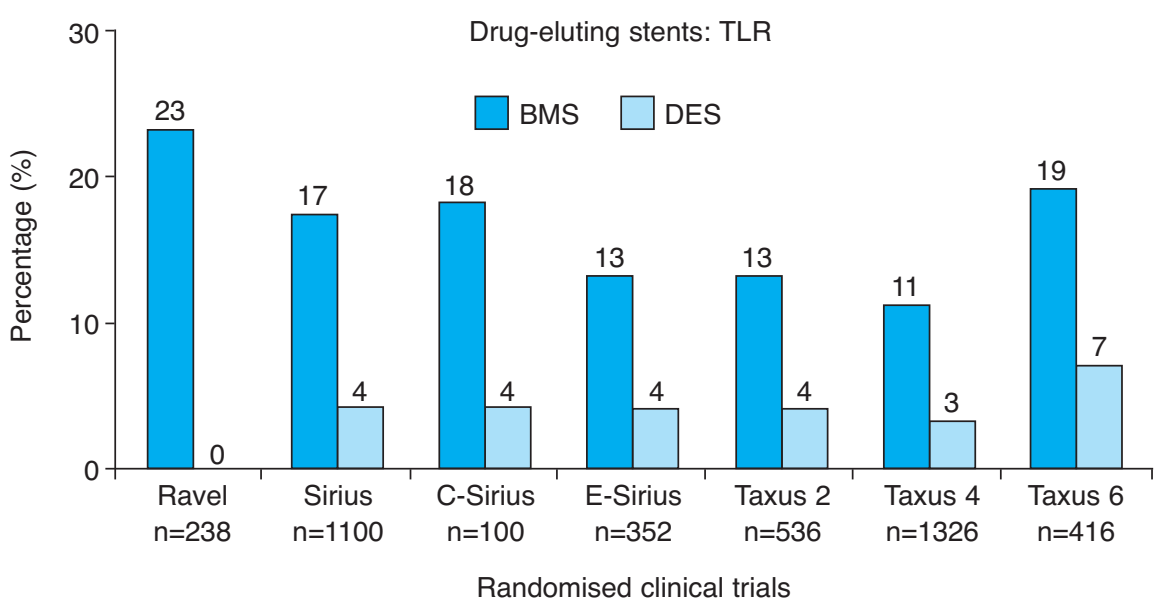

Fig 1. Target lesion revascularisation rates at 9-12 months in randomised clinical trials of drug-eluting stents (DES). BMS = bare metal stent control group; $n=$ total number of patients in the trials (both groups). Reproduced with kind permission of WileyBlackwell. ${ }^{9}$ 
glycoprotein IIb/IIIa receptor antagonists have been proven to reduce the risk of abrupt closure, stent thrombosis and peri-procedural myocardial infarction (MI), they have had little effect on restenosis.

Antiproliferative agents. Similarities between tumour growth and benign neointimal proliferation introduced the concept that immunosuppressant and cytotoxic agents might be beneficial for preventing in-stent restenosis. Incorporation of these agents into stent coatings using a number of techniques has now enabled delivery of the active agent directly to its site of action, while limiting systemic side effects. Critically, the ability to modify these coatings can permit sustained drug delivery following device implantation, ensuring that the agent is present when the target mechanism is physiologically active. With encouraging results in animal models, a number of antiproliferative agents have broken through into clinical trials. Thus far, the data have been dominated by two of these agents: sirolimus and paclitaxel.

RCT data have clearly shown that DES are associated with lower rates of restenosis than conventional bare metal stents. In fact, in RAVEL, the first study of DES in man, there was no clinically significant restenosis in patients treated with a sirolimus-eluting stent (SES). ${ }^{6}$ Low rates of restenosis and target lesion revascularisation/TVR are seen in both the SES (Cypher Stent, Cordis, USA) and paclitaxel-eluting stent (Taxus Stent, Boston Scientific, USA) when compared with bare metal stents (Fig 1). ${ }^{7-9}$

\section{Restenosis in the 'real world'}

Despite the considerable reduction in the need for repeat revascularisation, it is apparent that restenosis still occurs and at rates greater than seen in RCTs. This observation has been confirmed by data obtained from large registries monitoring the use and outcome of DES in 'real-world' populations, including patient groups often excluded from RCTs. These data sets have demonstrated that the excellent results seen in early RCTs are not applicable in all clinical scenarios, and helped to identify features that predispose to restenosis in DES. Predictors of higher rates of restenosis have been found to be diabetes mellitus, female sex, small coronary vessels, long lesions and previous CABG. ${ }^{10-12}$

Data regarding the treatment of restenosis in DES are limited, but the superiority of a second DES compared with all other available techniques has been demon- strated. Thus, at present the treatment of choice for DES in-stent restenosis is the implantation of a second DES.

\section{Drug-eluting stents and stent thrombosis}

Since the introduction of BMS, stent thrombosis has been recognised as a serious potential complication of stent implantation. ${ }^{13}$ Most episodes of stent thrombosis with BMS occur in the first 10 days following stent implantation, with thrombotic events rarely seen beyond 30 days. The introduction of dual-antiplatelet therapy (DAPT) with aspirin and clopidogrel reduced the rate of stent thrombosis in BMS to approximately $1 \% .{ }^{14}$ However, since the release and use of DES there have been numerous reports of stent thrombosis as late as three years after implantation - a phenomenon thought not to have been seen with BMS. ${ }^{15}$

\section{Safety of drug-eluting stents}

Sudden stent occlusion can lead to MI and sudden death, so this finding has generated a great deal of data and comment in both the scientific and popular press regarding the safety of DES. The pathophysiology of DES thrombosis is

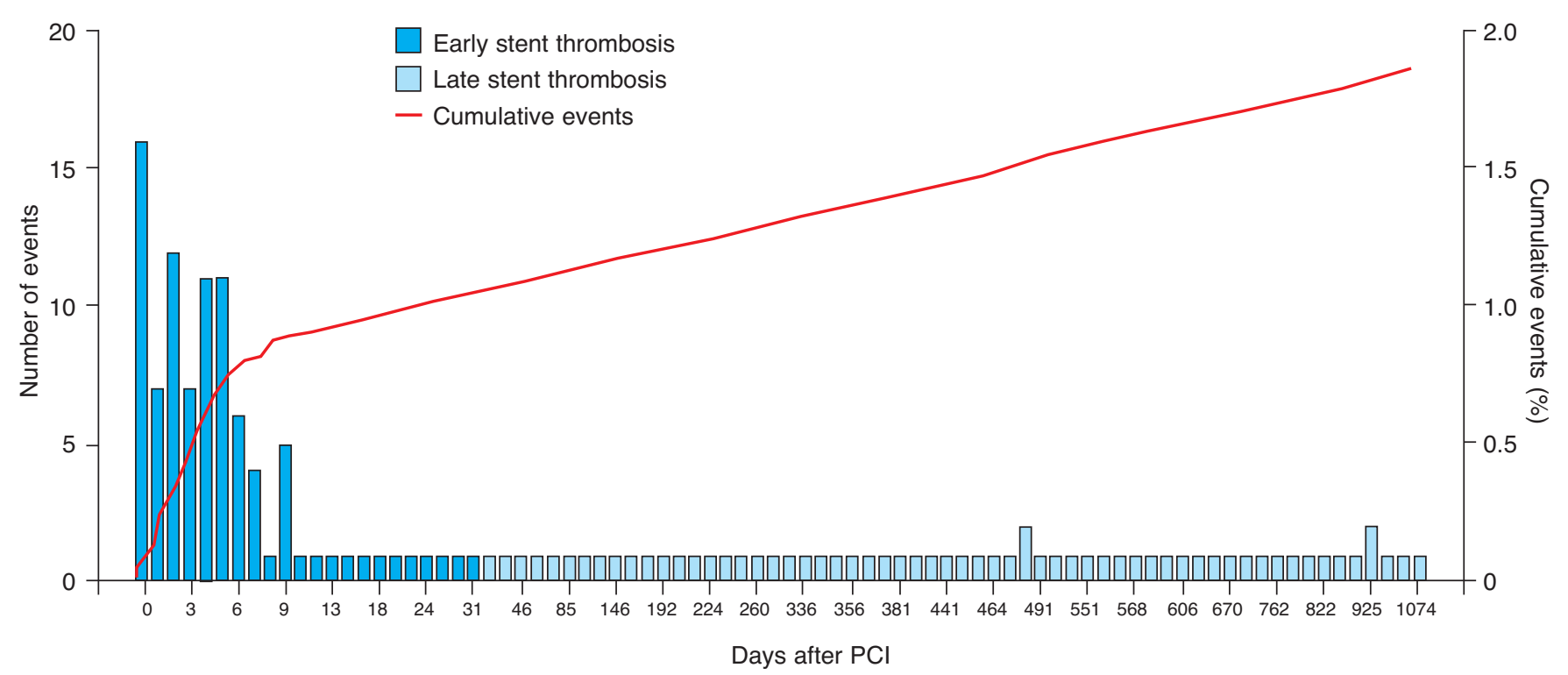

Fig 2. Occurrence and frequency of drug-eluting stent thrombosis over time. $\mathrm{PCl}=$ percutaneous coronary intervention. Reprinted with permission from Elsevier. ${ }^{17}$ 
complex, but known to be related to procedural factors, patient and lesion characteristics, antiplatelet therapy, thrombogenicity of the stent or drug delivery polymer and impaired vascular healing, leading to delayed re-endotheliasiation of the stent. ${ }^{16} \mathrm{~A}$ large non-randomised analysis of DES implantation in 8,146 patients found that late stent thrombosis occurred at a constant annual rate that accumulated to a stent thrombosis rate of $2.9 \%$ at three years' follow-up (Fig 2). ${ }^{17}$ Duration of antiplatelet therapy and complexity of cases are offered as potential explanations for the high rates of stent thrombosis seen in this study. Despite this, these data have confirmed that the rate of DES thrombosis in the real world is considerably higher than predicted from clinical trials.

\section{Prediction of drug-eluting stents thrombosis}

Premature cessation of DAPT has been identified as a strong predictor of DES thrombosis. ${ }^{18}$ Current recommendations are that DAPT should be continued for 12 months following DES implantation. ${ }^{19}$ It has been suggested that it be continued indefinitely to reduce further the continuing risk of DES thrombosis. This has important implications, including the possibility of increased risk of bleeding. Patients deemed at high risk of bleeding may be unsuitable for longterm DAPT.
In addition, the future medical problems in any individual are not predictable, so the situation may arise where an unplanned surgical intervention is needed and, if DAPT is stopped, the patient with a DES is exposed to a potential risk of late stent thrombosis. It is recommended that DAPT is not stopped prematurely and, if surgery is needed, either it be deferred until 12 months of DAPT has been completed or the surgeon operate with the patient continued on DAPT. There is no evidence that substituting heparin whilst DAPT is withdrawn will prevent stent thrombosis.

\section{Conclusions}

The advent of DES has produced a significant reduction in the need for repeat revascularisation in patients undergoing PCI with stent implantation, and thus has had a positive influence on the lives of many patients with CAD. However, as with many medical innovations, early euphoria has been replaced by cynicism regarding the potential limitations of this new technology. Emerging data have shown that DES are associated with a risk of thrombosis even late after implantation. This risk is increased in patients with diabetes, those with 'complex' coronary artery stenoses and those presenting with acute coronary syndromes. Unfortunately, these patient groups are at the highest risk of restenosis. It may be that the small increase in risk of stent thrombosis needs to be traded against the very

\section{Key Points}

Use of percutaneous angioplasty drug-eluting stents (DES) in the treatment of coronary artery disease reduces the rate of clinically apparent in-stent restenosis, reducing the need for repeat revascularisations

DES appear may be associated with an increased risk of stent thrombosis late (up to three years) after implantation; this is not seen with bare metal stents

The risk of DES thrombosis is greatly increased by the premature cessation of dual antiplatelet therapy (DAPT) with aspirin and clopidogrel

The currently recommended duration of DAPT following DES implantation is 12 months; this is not associated with an increased risk of bleeding

New technologies may help maintain low rates of restenosis and also reduce the risk of DES thrombosis

KEY WORDS: angioplasty, drug-eluting stents, revascularisation, review, stents

real reduction in restenosis. It is clear that the risks and benefits of DES in these and other subsets must be given careful consideration before their use.

The National Institute for Clinical Excellence guidance on the use of DES in the UK is that it should be considered in patients with small $(<3 \mathrm{~mm})$ diameter coronary arteries and long lesions $(>15 \mathrm{~mm})$ and should not be used in the setting of angioplasty for acute MI.

The use of DAPT is of paramount importance in optimising the results of DES implantation. The ideal duration of therapy has yet to be ascertained. The risks of stent thrombosis may need to be balanced against the potentially increased risk of haemorrhage associated with longer-term DAPT. At present, it is vital that patients are encouraged to comply with their medications following stent implantation and that DES should be avoided in situations where satisfactory continuation of DAPT cannot be expected.

Moreover, there is the real prospect that technology will evolve such that both restenosis and the risk of stent thrombosis are minimised. The development of biocompatible polymers for drug release, reabsorbable stents and drugs that promote stent endothelialisation all provide novel strategies that will undoubtedly lead to improvements in coronary stent performance.

Even in the era of effective secondary prevention the natural progress of CAD in an individual provides a greater threat to that patient's welfare than the potential risks associated with coronary stents. There does however remain a clear need for large RCTs to assess the safety and efficacy of currently available and new DES, with multinational prospective registries providing long-term 'real world' data regarding stent outcomes to guide the appropriate use of DES and the associated pharmacotherapy.

\section{References}

1 Fischman DL, Leon MB, Baim DS et al. A randomized comparison of coronary-stent placement and balloon angioplasty in the treatment of coronary artery disease. Stent Restenosis Study Investigators. N Engl J Med 1994;331:496-501. 
2 Serruys PW, de Jaegere P, Kiemeneij F et al. A comparison of balloon-expandable-stent implantation with balloon angioplasty in patients with coronary artery disease. Benestent Study Group. N Engl J Med 1994; 331:489-95.

3 Lagerqvist B, James SK, Stenestrand U et al; SCAAR Study Group. Long-term outcomes with drug-eluting stents versus bare-metal stents in Sweden. N Engl J Med 2007;356: 1009-19.

4 McFadden EP, Stabile E, Regar E et al. Late thrombosis in drug-eluting coronary stents after discontinuation of antiplatelet therapy. Lancet 2004;364:1519-21.

5 Serruys PW, Kutryk MJ, Ong AT. Coronary-artery stents. Review. $N$ Engl J Med 2006;354:483-95.

6 Morice MC, Serruys PW, Sousa JE et al. A randomized comparison of a sirolimuseluting stent with a standard stent for coronary revascularization. $N$ Engl J Med 2002;346:1773-80.

7 Fajadet J, Morice MC, Bode C et al. Maintenance of long-term clinical benefit with sirolimus-eluting coronary stents: three-year results of the RAVEL trial. Circulation 2005;111:1040-4.

8 Grube E, Silber S, Hauptmann KE et al. TAXUS I: six- and twelve-month results from a randomized, double-blind trial on a slow-release paclitaxel-eluting stent for de novo coronary lesions. Circulation 2003; 107:38-42.

9 Cowley MJ. Drug-eluting stent restenosis: incidence, predictors, mechanisms, and treatment. J Interv Cardiol 2006;19:s47-s53.

10 Lee CW, Park DW, Lee BK et al. Predictors of restenosis after placement of drugeluting stents in one or more coronary arteries. Am J Cardiol 2006;97:506-11.

11 Lemos PA, Serruys PW, van Domburg RT et al. Unrestricted utilization of sirolimuseluting stents compared with conventional bare stent implantation in the 'real world': the Rapamycin-Eluting Stent Evaluated At Rotterdam Cardiology Hospital (RESEARCH) registry. Circulation 2004; 109:190-5.

12 Ong AT, Serruys PW, Aoki J et al. The unrestricted use of paclitaxel - versus sirolimus - eluting stents for coronary artery disease in an unselected population: one-year results of the Taxus-Stent Evaluated At Rotterdam Cardiology Hospital (T-SEARCH) registry. J Am Coll Cardiol 2005;45:1135-41.

13 Serruys PW, Strauss BH, Beatt KJ et al. Angiographic follow-up after placement of a self-expanding coronary-artery stent. N Engl J Med 1991;324:13-7.

14 Bertrand ME, Rupprecht HJ, Urban P, Gershlick AH; CLASSICS Investigators. Double-blind study of the safety of clopidogrel with and without a loading dose in combination with aspirin compared with ticlopidine in combination with aspirin after coronary stenting: the clopidogrel aspirin stent international cooperative study (CLASSICS). Circulation 2000;102:624-9.

15 Ong AT, McFadden EP, Regar E et al. Late angiographic stent thrombosis (LAST) events with drug-eluting stents. J Am Coll Cardiol 2005;45:2088-92.

16 Lüscher TF, Steffl J, Eberli FR et al. Drugeluting stent and coronary thrombosis: biological mechanisms and clinical implications. Circulation 2007;115:1051-8.

17 Daemen J, Wenaweser P, Tsuchida K et al. Early and late coronary stent thrombosis of sirolimus-eluting and paclitaxel-eluting stents in routine clinical practice: data from a large two-institutional cohort study. Lancet 2007;369:667-78.

18 Iakovou I, Schmidt T, Bonizzoni E et al. Incidence, predictors, and outcome of thrombosis after successful implantation of drug-eluting stents. JAMA 2005;293:2126-30.

19 Yusuf S, Zhao F, Mehta SR et al. Effects of clopidogrel in addition to aspirin in patients with acute coronary syndromes without ST-segment elevation. $N$ Engl J Med 2001;345:494-502. 